University of Vermont

UVM ScholarWorks

University Libraries Faculty and Staff

Publications

University Libraries

2014

\title{
Library Support Of Mobile Resources During Clinical Clerkships
}

Jeanene C. Light

jlight@uvm.edu

Alice Stokes

98astoke@uvm.edu

Laura L. Haines

Ihaines@uvm.edu

Follow this and additional works at: https://scholarworks.uvm.edu/libfacpub

Part of the Library and Information Science Commons, and the Medical Education Commons

\section{Recommended Citation}

Light, Jeanene C.; Stokes, Alice; and Haines, Laura L., "Library Support Of Mobile Resources During Clinical Clerkships" (2014). University Libraries Faculty and Staff Publications. 18.

https://scholarworks.uvm.edu/libfacpub/18

This Article is brought to you for free and open access by the University Libraries at UVM ScholarWorks. It has been accepted for inclusion in University Libraries Faculty and Staff Publications by an authorized administrator of UVM ScholarWorks. For more information, please contact scholarworks@uvm.edu. 
This is an electronic version of an article published in Medical Reference Services

Quarterly, Volume: 33, Issue: 02, pages 179 - 194. Medical Reference Services Quarterly is available online at:

http://www.tandfonline.com/doi/full/10.1080/02763869.2014.897519.

\title{
Library Support of Mobile Resources During Clinical Clerkships
}

\author{
Alice Stokes \\ Jeanene Light \\ Laura L. Haines
}

\begin{abstract}
In response to frequent use of mobile devices among medical students, Dana Medical Library at the University of Vermont provided mobile resource support to medical students preparing for clerkships. The librarians offered group instruction, individual assistance, and an online subject guide. These activities were assessed through evaluations, web statistics, and a survey. Survey questions gathered data on access to mobile devices, use of library-licensed mobile resources, and benefits and barriers to use in the clinical setting. The majority of survey respondents believed access to mobile resources improved their clerkship experience and contributed to comparable educational experiences across clerkship sites. Researchers found that library support impacted student perception of the value of mobile resources in the clerkship experience.
\end{abstract}


KEYWORDS. Academic health sciences libraries, clerkships, handhelds, library instruction, medical education, medical students, mobile devices

\section{Authors.}

Alice Stokes, MLIS (alice.stokes@uvm.edu) is Information Services Librarian, Dana Medical Library, University of Vermont, 81 Colchester Avenue, Burlington, VT 05405. Jeanene Light, MLS (jeanene.light@uvm.edu) is Collection Development Librarian, Dana Medical Library, University of Vermont, 81 Colchester Avenue, Burlington, VT 05405.

Laura L. Haines, MLS (laura.haines@uvm.edu) is Information Services Librarian, Dana Medical Library, University of Vermont, 81 Colchester Avenue, Burlington, VT 05405. 


\section{INTRODUCTION}

The use of mobile devices has increased greatly in recent years. The 2013 Pew Internet Project reports that the number of Americans aged 16 and older who own tablet computers has grown to $35 \%$, and those owning some type of e-reading device has grown to $24 \% .{ }^{1}$ Mobile devices are especially ubiquitous in health care settings and are becoming common in medical education, where medical "apps" and mobile optimized websites are numerous. A recent study of more than 3,700 physicians indicated more than $30 \%$ now use tablets, with $20 \%$ using them in a clinical setting. ${ }^{2}$ One in four has both a tablet and a smartphone. A 2009 systematic review identified 13 studies that demonstrated the ability of mobile handheld devices to "positively impact on areas of rapid response, error prevention, and data management and accessibility" in the health care setting. ${ }^{3}$

Overall, the literature on mobile use in a health care setting tends to focus on physicians and residents rather than medical students. One study describes the use of mobile devices to communicate patient care information to other members of the health care team via e-mail or text. ${ }^{4}$ Most articles have been descriptive in nature, focusing on mobile devices preferred and more general usage habits. Favored resources in clinical education include point-of-care databases, drug guides, medical calculators, and immunization schedules. Other tools described are: clinical decision support software, practice guidelines, patient education materials, and physician order sets. ${ }^{5}$

Although there is widespread belief that mobile devices are helpful and convenient in the clinical setting, the literature reveals an overall lack of institutional 
support, standardization of resources, and training in medical education. ${ }^{6}$ Some authors have called for more study on issues related to privacy and professionalism. ${ }^{7}$ Overall, few studies focus on either pedagogy or learning outcomes for medical students in a clinical setting and even fewer have sought to measure whether mobile resources usage contributes to improved patient outcomes. ${ }^{8}$

\section{BACKGROUND}

The University of Vermont's Dana Medical Library has actively supported mobile computing in the health sciences since handheld devices were first introduced. More recently, recognizing medical student interest and usage of mobile devices, this support has taken the form of classroom-based instruction, online subject guides, and individual assistance at the library's information desk.

The University of Vermont's College of Medicine enrolls approximately 400 students. In their third year of study, students participate in clinical clerkships in Pediatrics, Obstetrics and Gynecology, Family Medicine, Surgery, Neurology, Internal Medicine (in-patient and out-patient), and Psychiatry. The clerkships are distributed throughout four practice sites: Fletcher Allen Health Care (Burlington, Vermont);

Danbury Medical Center (Danbury, Connecticut); St. Mary’s Hospital (West Palm Beach, Florida), and Eastern Maine Medical Center (Bangor, Maine).

Many clerkship students bring mobile devices, including smartphones, to their practice site(s). This study assessed current methods of supporting medical students utilizing mobile devices in the clinical setting, resources used, and barriers to mobile use. 
Of particular interest was whether mobile devices might contribute to "comparable educational experiences" across clerkship sites, one of the Liaison Committee on Medical Education requirements for accreditation of medical schools. ${ }^{9}$

\section{LIBRARY SERVICES FOR CLERKSHIP STUDENTS USING MOBILE DEVICES}

\section{Mobile Instruction}

During the 2011-2012 academic year, Dana Medical Library offered optional group and individual instruction on clinical mobile resources. All 111 students in the University of Vermont College of Medicine Class of 2014 had the opportunity to attend one of two 45minute sessions on mobile apps for clinical use during the clerkship orientation week immediately prior to their first clinical rotation (March 2012). Class content included an overview of apps available through library subscriptions, their clinical relevance, and instruction on how to download and authenticate the apps. Students were asked to complete a brief course evaluation at the end of the class.

According to attendance records, 54 of the 111 (49\%) students attended a group instructional session. A written evaluation form was given to each of the 54 attendees, and 19 completed it at a rate of $35 \%$. The evaluations were overwhelmingly positive with all 19 rating "strongly agree" or "agree" to statements about the instructor's preparation and attitude, the presentation's organization, and the helpfulness of the session. Sixteen "strongly agreed" and three "agreed" to the statement, "This session will help me with my professional work." Written comments indicated that the content was new for most 
students, and that they did not realize that Dana Medical Library offered access to mobile versions of popular library resources. Comments also indicated a wish for even more discussion of point-of-care and drug apps, including those not licensed by the library.

In addition to group instruction, individual instruction and technical support were available to students at the reference desk or by direct consultation with the mobile resources librarian, whether or not they attended the class. Technical support included distribution of authentication codes and troubleshooting. Opportunities for individual assistance were promoted in the class and on the mobile subject guide.

\section{Online Subject Guide}

An online subject guide <http://danaguides.uvm.edu/mobile> provided detailed instructions for finding and installing library-licensed mobile resources. The guide, shown in Figure 1, included the name of each resource, a link, a brief description, compatible platforms, and detailed instructions for downloading and authentication. Contact information for the mobile resources librarian was included on the guide. A link to the subject guide was placed on the library home page, and the guide was promoted during the class, in the College of Medicine course management system, and by librarians and staff. The subject guide was created using SpringShare's LibGuides software. Usage statistics were obtained from LibGuides. 


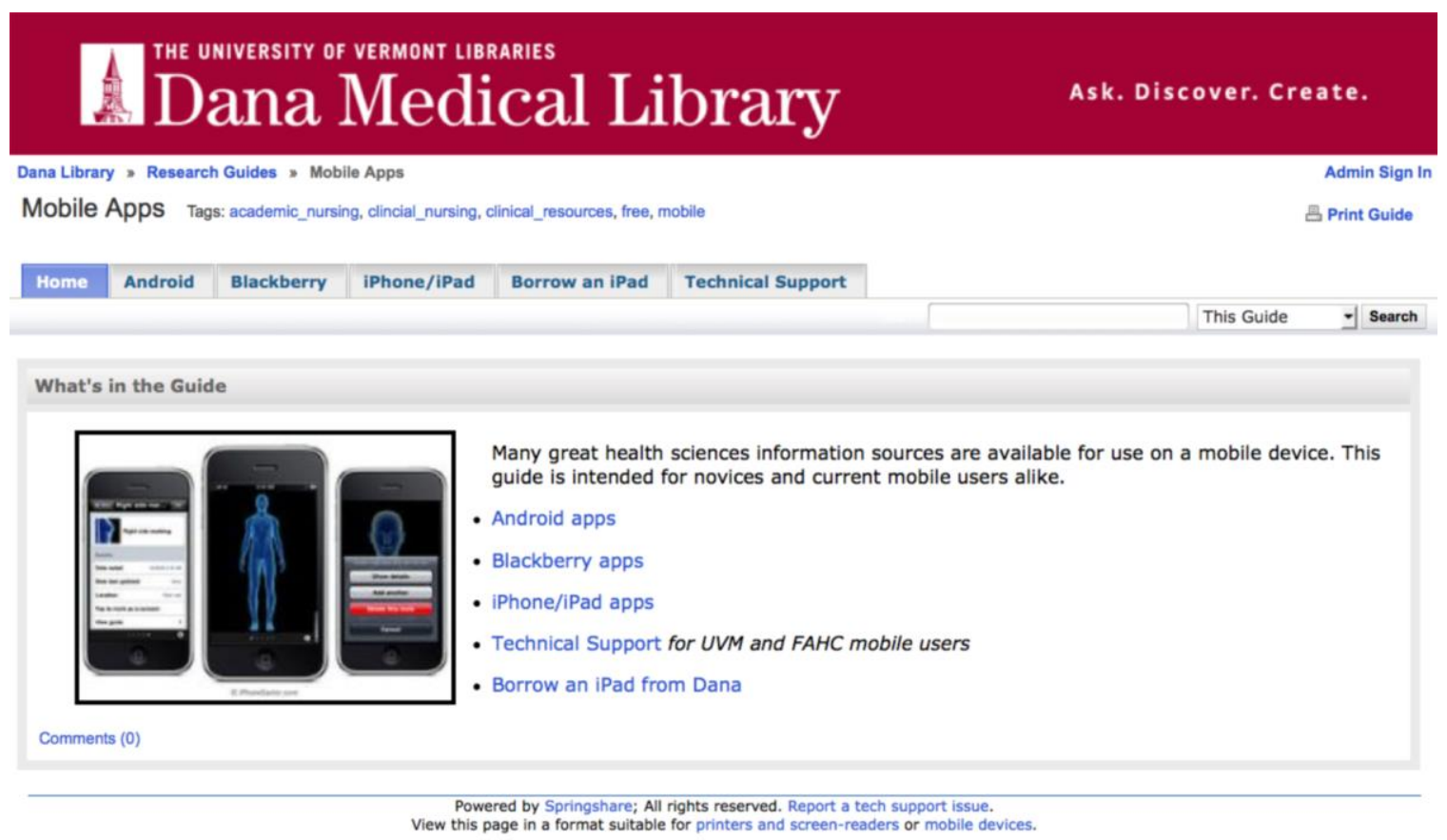

Figure 1. Online subject guide

Figure 2 depicts usage statistics from LibGuides showing the variation in traffic to the mobile subject guide throughout 2012. Use of the subject guide in March, when the mobile instruction session occurred, was $218 \%$ higher than the previous month. Average use of the guide remained measurably higher in the six-month period following the class. 


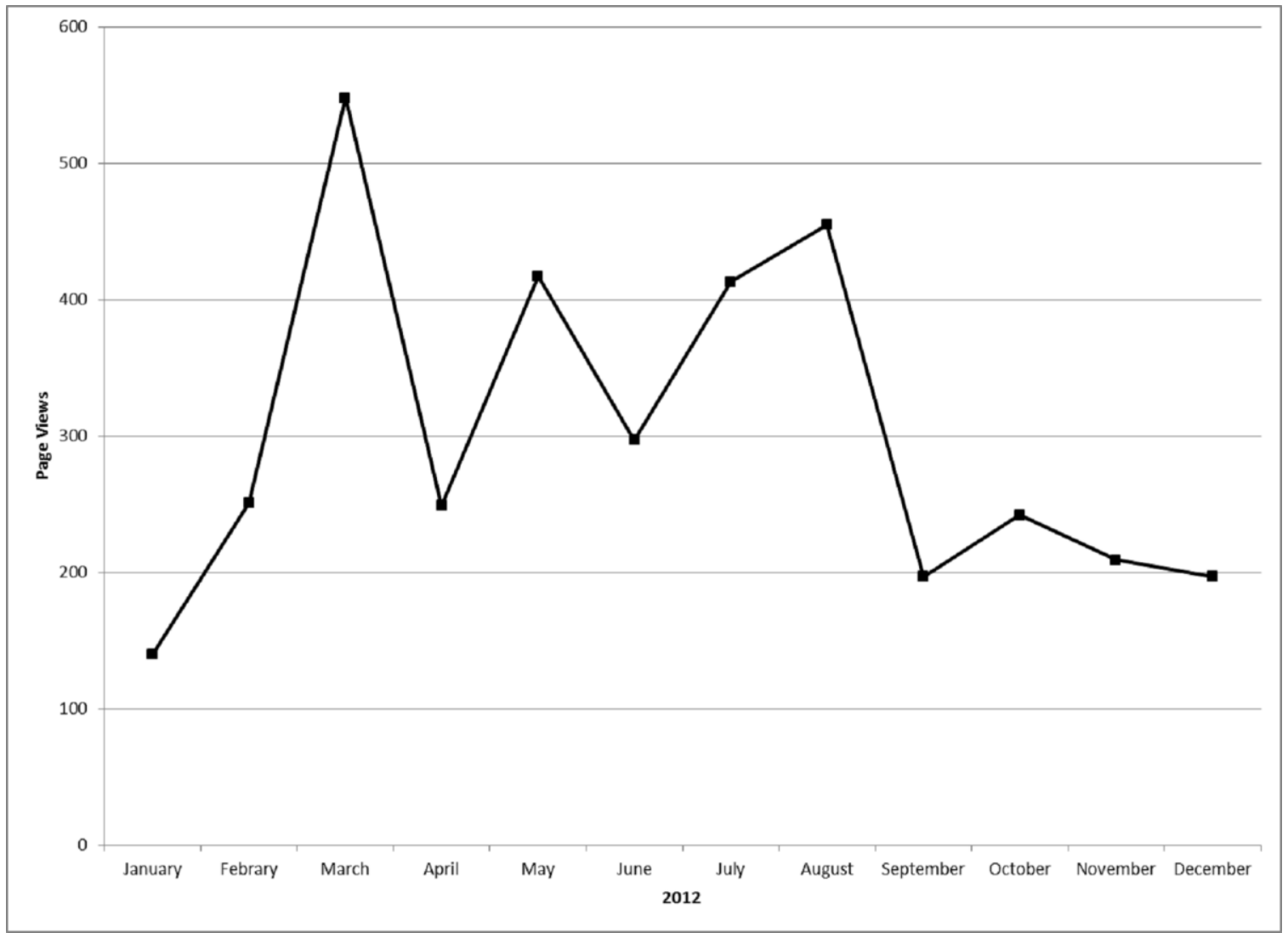

FIGURE 2. Monthly page views of the mobile subject guide, January-December 2012

\section{SURVEY OF CLERKSHIP STUDENTS}

\section{Survey Methods}

A survey was developed to assess library support of mobile resource use during the clerkships. The survey was sent to all 111 students in the University of Vermont College of Medicine Class of 2014. Survey questions gathered data on access to mobile devices, relevance of library instruction, use of library-licensed mobile resources during the clerkships, benefits and barriers to mobile device use in the clinical setting, and impact of access to mobile resources on educational experiences across clerkship sites. The survey 
was administered over a two-week period in November 2012. At that time, the students had completed four clerkships and were mid-way through a fifth rotation.

The survey consisted of 26 questions. A draft was created by two researchers and reviewed by an additional two researchers. The survey was pre-tested by five University of Vermont College of Medicine fourth-year students and two library faculty members. Revisions were made based on results of the pre-testing. The final survey instrument and protocol was reviewed and granted exempt status by the Institutional Review Board of the University of Vermont. Questions 1-2 collected demographic information and were optional. Questions 3-7 related to ownership of a mobile device. Questions 8-11 and 1518 pertained to library instruction on mobile resources. Questions 12-14 were about the online subject guide. Questions 19-26 concerned the use of mobile devices and resources during clerkship.

The complete survey instrument is provided in the Appendix. The final instrument was created using SurveyMonkey <http://www.surveymonkey.com>. A link to the online survey was distributed via e-mail to the College of Medicine Class of 2014. Survey responses were anonymous, and respondents were invited to enter a drawing for a gift card. The drawing was carried out using SurveyMonkey's Rewards function, which allowed respondents' answers and entry into the drawing to be independent. Results of the survey were analyzed using SurveyMonkey's Analyze tool and by review of the raw data.

\section{Survey Results}


Thirty-one students out of 111 completed the survey at a completion rate of $28 \%$. The demographics of the students completing the survey were representative of the demographics of the class as a whole. Of the total 31 respondents, 55\% were women, and the majority of respondents (61\%) fell into the 25-29 year old age group.

Use of Library Support. Table 1 provides data on how many respondents used some form of mobile support offered by the library, and whether or not they found that support helpful. Eighteen survey respondents (58\% of total survey respondents) reported that they had attended one of the classes offering mobile instruction the week before the first clinical rotation. The main reason cited for not attending the class was lack of time during that busy week of preparation for clerkship. Two respondents indicated that they did not own a mobile device when the class was offered, but acquired one by the time the survey was administered. Two respondents stated that they felt they could find the information elsewhere. Of the $58 \%$ of respondents who attended the instruction session on mobile resources, $94 \%$ found the class helpful. Suggestions for improving the class included having vendor authentication codes available during the session and covering non-library licensed clinical apps.

TABLE 1. Mobile support use and satisfaction

\begin{tabular}{|c|c|c|c|c|c|}
\hline Attended Class & Number & Percentage & $\begin{array}{c}\text { Class } \\
\text { Helpful }\end{array}$ & Number & Percentage \\
\hline Yes & 18 & $58.1 \%$ & $Y e s$ & 17 & $94.4 \%$ \\
\hline No & 13 & $41.9 \%$ & No & 1 & $5.6 \%$ \\
\hline $\begin{array}{c}\text { Sought Help } \\
\text { from Library }\end{array}$ & Number & Percentage & $\begin{array}{c}\text { Assistance } \\
\text { Helpful }\end{array}$ & Number & Percentage \\
\hline
\end{tabular}




\begin{tabular}{|c|c|c|c|c|c|}
\hline Yes & 8 & $25.8 \%$ & Yes & 8 & $100 \%$ \\
\hline No & 23 & $74.2 \%$ & No & 0 & $0 \%$ \\
\hline $\begin{array}{c}\text { Looked at } \\
\text { Online Guide }\end{array}$ & Number & Percentage & $\begin{array}{c}\text { Guide } \\
\text { Helpful }\end{array}$ & Number & Percentage \\
\hline Yes & 16 & $51.6 \%$ & Yes & 14 & $87.5 \%$ \\
\hline No & 15 & $48.4 \%$ & No & 2 & $12.5 \%$ \\
\hline
\end{tabular}

Approximately $25 \%$ of respondents sought individual assistance at the library, and reported it was helpful. Reasons stated for not seeking assistance included not having specific needs and not having enough time. While comments about the individual assistance were positive, one respondent suggested that assistance with non-library licensed apps would also be welcomed. Thirty-seven mobile access codes to librarylicensed DynaMed were distributed at the reference desk in the month following the class, as opposed to only two in the month before the class.

Half of the survey respondents looked at the online subject guide; $88 \%$ of those found it helpful. Those survey respondents who did not look at the subject guide reported that they were unaware of its existence. Sixty percent of students who reported not looking at the subject guide also did not attend the class.

Mobile Devices, Wireless Access, and Barriers to Use. All respondents to the survey owned a mobile device, despite efforts to recruit both mobile users and non-users. The survey asked students to indicate what devices they owned, and many indicated they owned or used more than one device. Respondents showed a preference for Apple mobile devices, with 23 respondents indicating they had an iPhone, five an iPod Touch, and six 
an iPad. Six respondents had an Android device, and only one reported having a Blackberry device.

Survey respondents were asked about barriers to the use of mobile devices at clerkship sites, as shown in Figure 3. The most common barrier to mobile use cited was "Not the right kind of information/ apps" by 14 respondents (45.2\%). "Not enough time" was the second most frequently cited barrier, and "No wireless/connectivity" and "Climate/culture of hospital did not support use" were both cited as barriers by nine respondents. Eight respondents reported that they did not encounter any barriers. A few respondents commented on barriers. One person wanted access to more resources that did not require connectivity to the Internet. Another remarked that, "I found myself always needing to explain that I was using my phone for apps, not texting."

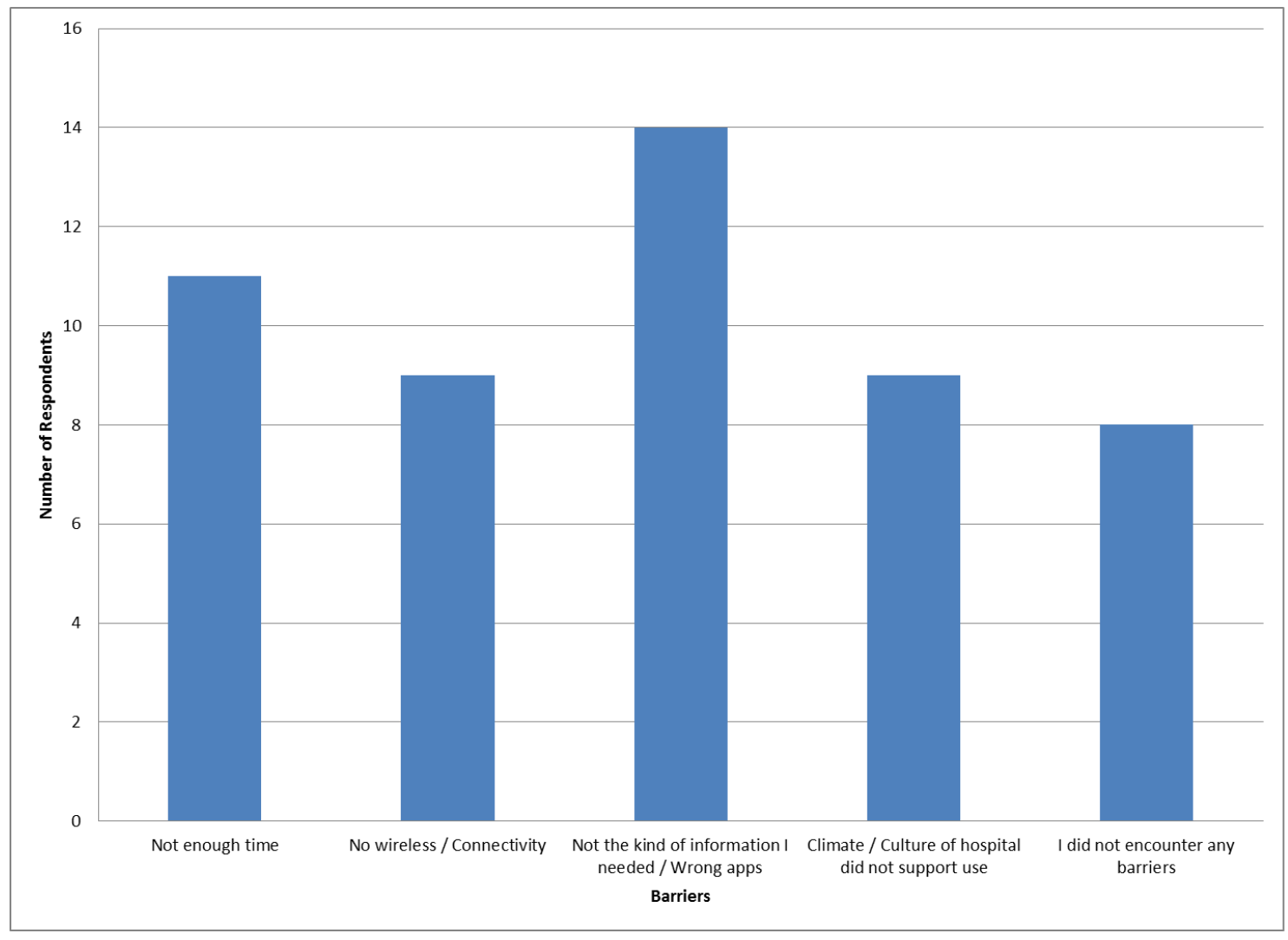

FIGURE 3. Barriers to mobile use during clerkship 
Students were also asked to rate the quality of access to wireless networks at each clerkship site. Wireless access was generally rated "excellent" or "good" at all four sites. It must be noted, however, that while all respondents attended a clerkship in Burlington, many had not been to the other three sites. In fact, over half of the survey respondents had not been to West Palm Beach or Bangor.

Use of Mobile Resources. The majority (90\%) of respondents agreed to the statement, "Having access to mobile apps during this clerkship allowed me to look up patient care information quickly." Respondents were given a list of library-licensed and free mobile apps and asked to indicate which ones they used during their clerkships. Epocrates and Medscape, two free resources, were used most frequently. The other mobile resources cited most were: UpToDate, DynaMed, Micromedex, clinical calculators, immunization schedules, First Consult, and USMLE World. Many apps were mentioned only once by respondents, but fell into the following categories: medical abbreviations, academic journals, dictation tools, lab values, electronic health records, and guidelines. Certain library-licensed applications, namely Natural Standard, Web of Science, and Clinical Pharmacology, were reported as never having been used by survey respondents. Students were also asked which apps or information they wished to have, and eight respondents specifically mentioned wanting access to an UpToDate app.

Mobile Device Use and the Clerkship Experience. The clerkships with the highest percentage of attendees who brought a mobile device to the clerkship experience were Family Medicine, Inpatient Medicine, and Pediatrics. The majority of respondents agreed to the statement "Having access to mobile apps during this clerkship improved my 
clerkship experience," but numbers varied according to department: Family Medicine (100\%, $n=17)$, Inpatient Medicine (81\%, $n=21)$, Neurology $(85 \%, n=20), \mathrm{OB} / \mathrm{GYN}$ (69\%, $n=16)$, Outpatient Medicine (21\%, $n=21)$, Pediatrics (80\%, $n=15)$, Psychiatry $(84 \%, n=19)$, Surgery $(79 \%, n=19)$. The majority of survey respondents $(71 \%)$ agreed or strongly agreed to the statement, "I feel that having mobile access to point-of-care information helped me have comparable educational experiences across clerkship sites."

\section{DISCUSSION}

Overall, library support was highly rated by clerkship students. Students in the Class of 2014 displayed significant interest in learning about mobile resources for clinical use. In fact, nearly half of the cohort attended the optional instructional session. Comments from students indicated that the content covered in the instruction session was new to most students. According to qualitative feedback from the survey, library instruction could be improved by providing in-class assistance installing and authenticating apps. While many medical students are using mobile devices for personal and academic reasons, there appears to be a need for information about resources for clinical use. This apparent need, coupled with positive feedback about instruction, argues for continued focus on education about mobile resources.

A large majority of students who viewed the online subject guide indicated that it was helpful; however, nearly half of the survey respondents did not use the guide. This suggests a need for further promotion and marketing of mobile resource support by the library. The subject guide continues to be updated to reflect current mobile resources and 
user needs. Recommended non-library licensed apps have been added to assist students in selecting appropriate apps useful in the clinical setting. While the usage of the mobile subject guide remains high (it is the most frequently accessed Dana Medical Library subject guide), promotion of the guide to clerkship students in particular may be warranted.

While not all students took advantage of library support, almost all of the respondents who did report taking a mobile device on a rotation agreed it facilitated access to clinical information and improved the clerkship experience. Of survey respondents, $83.4 \%$ who sought any assistance from the library agreed to the statement, "I feel that having mobile access to point-of-care information helped me have comparable educational experiences across clerkship sites." Only $28.6 \%$ of those who did not get any assistance agreed with the statement. Researchers had been concerned that access to wireless networks might be uneven across sites. However, students generally rated wireless access as "excellent" or "good" and therefore not a significant barrier to mobile resource use.

Researchers were surprised that two of the most commonly used apps (ePocrates and Medscape) were not library-licensed apps. On a related note, the most common barrier cited by respondents was a discrepancy between their clinical information needs and available apps. This implies that there is a role for the library in curating a list of library and non-library licensed apps for use in the clinical setting. Another reported barrier was a lack of time to use mobile apps during clerkship.

Many students indicated a desire for mobile access to UpToDate. At the time of the survey, mobile access to UpToDate was limited to on-campus use of their mobile 
optimized site. A license signed in October 2012 provided clerkship students off-site access to the mobile-friendly site. Furthermore, institutional access to the UpToDate app became available in June 2013. These means of mobile access to UpToDate have likely filled a significant need for clerkship students.

Finally, there is concern that issues such as patient privacy and professionalism need to be addressed as students blend personal and professional mobile computing in a single device. As one student noted, patients or preceptors may not know if a student is using a device for personal or professional purposes in the clinical setting. Guidelines for professional use of mobile resources could help students navigate these issues. Although it appears that mobile device usage was more accepted in certain clerkship departments than others, the researchers do not know why this might be true. An area for further exploration may be medical specialty attitudes toward mobile device use. Considering the increasing use of mobile medical applications, departments may want to outline their own expectations of mobile resource use in the clinical setting for clerkship students and attending physicians alike.

Some changes in library support of mobile resources for clerkship have already been implemented. Students in the University of Vermont College of Medicine Class of 2015 were issued Android tablets for use during their clerkship year. Library instruction and support of mobile resources for clerkships was tailored to cover resources for the Android tablet. The instruction session was made mandatory and expanded to include support in installing and authenticating apps as requested.

The findings of this study may be limited in applicability to other libraries. One limitation noted was the low survey response rate. A response bias is likely; non-users of 
mobile devices did not respond to the survey. A further consideration was that, as noted, students had not completed all seven clerkships. In fact, over half had not been to two of the clerkship sites. Finally, another limitation of any such study is the rapid and emerging nature of the technology itself. Although efforts were made to review the most current literature available, new reports are published every week.

\section{CONCLUSION}

Mobile technology use has become widespread in medicine, and clerkship students are increasingly using mobile resources to meet clinical information needs. Library support of licensed and non-licensed clinical resources may enhance students' clerkship experience and facilitate comparable educational experiences across clerkship sites. Opportunities for academic health sciences libraries to support clerkship students include instruction, resource curation, and technical support. Feedback from the cohort of students involved in this study may be used to improve library support of mobile resources for clerkship experiences in the future.

Received: November 27, 2013

Revised: January 7, 2014

Accepted: February 2, 2014

\section{REFERENCES}


1. Rainie, L., and A. Smith. "Tablet and E-Reader Ownership Update.” Pew Internet \& American Life Project. October 2013.

http://pewinternet.org/ /media//Files/Reports/2013/PIP_Tablets\%20and\%20ereaders\%20update_101813.pdf.

2. Dolan, B. "Survey: 1 in 4 Mds Have Both Tablet, Smartphone.” June 22, 2011. http://mobihealthnews.com/11338/survey-1-in-4-mds-have-both-tablet-smartphone/. 3. Prgomet, M., A. Georgiou, and J. I. Westbrook. "The Impact of Mobile Handheld Technology on Hospital Physicians' Work Practices and Patient Care: A Systematic Review." J Am Med Inform Assoc 16, no. 6 (November-December 2009): 792-801. 4. Wallace, S., M. Clark, and J. White. “'It's on My iPhone': Attitudes to the Use of Mobile Computing Devices in Medical Education, a Mixed-Methods Study." BMJ Open 2, no. 4 (2012).

5. Kho, A., L. E. Henderson, D. D. Dressler, and S. Kripalani. "Use of Handheld Computers in Medical Education. A Systematic Review." J Gen Intern Med 21, no. 5 (May 2006): 531-537.

6. Sandars, J. "Technology and the Delivery of the Curriculum of the Future: Opportunities and Challenges." Med Teach 34, no. 7 (2012): 534-538.

7. Whipple, E. C., K. L. Allgood, and E. M. Larue. "Third-Year Medical Students' Knowledge of Privacy and Security Issues Concerning Mobile Devices." Med Teach 34, no. 8 (2012): e532-48.

8. Davies, B. S., J. Rafique, T. R. Vincent et al. "Mobile Medical Education (Momed) How Mobile Information Resources Contribute to Learning for Undergraduate Clinical Students - a Mixed Methods Study.” BMC Med Educ 12 (2012): 1. 
9. Liaison Committee on Medical Education. Functions and Structure of a Medical

School: Standards for Accreditation of Medical Education Programs Leading to the M.D.

Degree. June 2012. https://www.lcme.org/publications/functions2012may.pdf. 